\title{
The impact assessment of thermal pollution on subtidal sessile assemblages: a case study from Mediterranean rocky reefs
}

\author{
Stanislao Bevilacqua ${ }^{1,2, *}$, Samsa Clara ${ }^{1}$, Antonio Terlizzi ${ }^{1,2,3}$ \\ ${ }^{1}$ Deptartment of Life Sciences, University of Trieste, 34127 Trieste, Italy \\ ${ }^{2}$ CoNiSMa, Piazzale Flaminio, 9, Roma, Italy \\ ${ }^{3}$ Stazione Zoologica Anton Dohrn, 80121 Napoli, Italy \\ *Corresponding author e-mail: sbevilacqua@units.it
}

Received: 1 September 2020 / Accepted: 18 October 2020

\begin{abstract}
Coastal power plants generally use seawater as cooling fluid, discharging heated waters into the sea after the cooling process. The ensuing increase in seawater temperature could affect the marine biota in the nearby areas, causing alterations at different level of biological organization, from individuals to populations and assemblages. In the Mediterranean Sea, few attempts have been made to assess the effects of this point sources of thermal pollution, especially on rocky habitats. Here, we investigated the putative impact of a thermal effluent from one of the largest European coal-fired coastal power plants on sessile assemblages of subtidal rocky reefs. Sessile assemblages on rocky substrates were photographically sampled at one location near the effluent $(I)$, and at two control locations $(C s)$ virtually unaffected by thermal discharge. An asymmetrical after-control impact experimental design was employed to test the hypothesis that the thermal discharge significantly modified sessile assemblages at $I$ if compared to Cs. We detected significant differences in assemblages at $I$ versus $C s$, indicating a clear effect of the effluent on assemblage structure. Such differences were mostly due to shift in dominance among macroalgae between $I$ and $C s$, which likely depended on different tolerance limits of species to increased seawater temperature and other sources of disturbance associated to the effluent, such as increased sedimentation rates and water turbidity. Our findings stressed the need for further investigations of the impact of thermal effluents on marine communities, considering the potential synergistic effects of climate change especially in the Mediterranean Sea.
\end{abstract}

Keywords: Asymmetrical design, climate change, coal-fired power plants, macrobenthos, thermal effluents

\section{Introduction}

There are about 6300 operating power plants worldwide relying on combustion of fossil fuels (coal, gas, and oil) or nuclear reactors (WPPD, World Power Plant Database, 2020). They are commonly located close to rivers, lakes, or in coastal zones, to exploit water for cooling their energygenerating units. In power plants positioned onshore, seawater at ambient temperature is withdrawn through intake structures, generally placed on the sea bottom near the coastline, pumped in the cooling system of the power plant and, after the cooling process, discharged at a higher tempera- ture into the sea. Temperature ranges of discharged heated waters are often imposed by law, although legal limits may change with country. In Europe, for example, admitted limits for temperature of thermal effluents range between 7 and $12^{\circ} \mathrm{C}$ higher than the ambient value, if related to the increase of seawater temperature in the nearby marine water body, should not exceed $1-3{ }^{\circ} \mathrm{C}$ at a distance that varies from few tens of meters to $1 \mathrm{~km}$ from the outfall (Gaeta et al., 2020).

Since water temperature influences a number of biological processes in marine organisms, including metabolism, physiology, reproduction, behaviour (Sylvester, 1970; 
Bamber, 1990; Sanford, 1999; Lukšienè et al., 2000; Jang et al., 2009; Harvey et al., 2013; Givan et al., 2018), thermal pollution from coastal power plants has raised wide concerns on potential effects on aquatic populations and communities (Bush et al., 1974; Walther et al., 2009). The effect of the discharge of heated waters may cause detrimental effects on marine biodiversity, leading to drastic changes in the structure of assemblages, and affecting all marine ecological compartments, including plankton (Choi et al., 2002; Lin et al., 2018), benthos (Barnett, 1972; Deabes, 2020), and fish (Teixeira et al., 2012; White \& Wahl, 2020). For example, several studies found a significant reduction in abundance and diversity of phytoplankton and zooplankton (Lin et al., 2018), but also of macroinvertebrates (Teixeira et al., 2012; Deabes, 2020) and fish assemblages (Teixeira et al., 2009; 2012) in areas adjacent to thermal effluents. Mechanisms driving such changes are manifold, and often related to physiological chronic stress (Kim et al. 2017), or to the disruption of normal reproductive timing or growth processes (Barnett, 1972) induced by the increased water temperature, which in turn constrain the persistence of viable populations, especially those of stenothermal organisms (Bamber, 1990).

In most cases, the influence of thermal discharge on marine assemblages is limited within few hundreds of meters from the effluent (e.g., Bamber, 1990; Choi et al., 2002; Teixeira et al., 2009; Deabes, 2020). However, the effects of thermal pollution on marine species may be exacerbated by the increase of seawater temperature under future global warming scenarios (Keser et al., 2005; Coulter et al., 2014; Worthington et al., 2015). Coastal areas affected by thermal discharges could also provide suitable habitats for non-native species from warmer marine regions (Bamber, 1990; Baker et al., 2007; Wolf et al., 2014), and facilitate their recruitment and spread in the native assemblages, with potential ecological implications for the whole ecosystem (Walther et al., 2009). Intensified effects of thermal pollution may be envisaged in marine areas representing hot spots for climate change, particularly exposed to biological invasions and warming, such as the Mediterranean Sea (Rilov \& Galil, 2009; Rivetti et al., 2014; Katsanevakis et al., 2014; Guarnieri et al. 2017; Yeruham et al., 2020). In this basin, more than 60 operating power plants using seawater as cooling fluid are located along the coast, and many other are under construction or projected (WPPD, 2020). Few attempts, however, have been done to understand the potential outcomes of thermal discharge on Mediterranean marine assemblages, and most of them centred on soft bottom infauna (e.g., Crema \& Bonvicini Pagliai, 1980; Lardicci et al., 1999; Deabes, 2020), whereas even less case studies investigated the consequences of thermal pollution on hard bottoms and, however, they were focused on single taxa (e.g., Arieli et al., 2011).
In this study, we assessed the effects of thermal discharge from one of the largest coal-fired coastal power plants in Europe on Mediterranean rocky reefs. An asymmetrical experimental design contrasting the discharge area with unaffected control areas was structured to test whether the presence of the thermal effluent could cause changes in the structure and diversity of subtidal sessile assemblages.

\section{Study area}

The study area is located along the coast of SE Italy (S Adriatic, Mediterranean Sea), near the town of Brindisi, where a thermal effluent discharges the cooling waters from the coal-fired power plant 'Federico II' (Fig. 1). Along the coastline, sandy beaches alternate with silt-clay cliffs, whereas the sea bottom until $10 \mathrm{~m}$ depth is characterized by a mosaic of sandy habitats, Posidonia oceanica (L.) Delile, 1813 seagrass beds and rocky reefs, the latter being more common in the north sector of the study area. The power plant is one of the largest coal-fired energy plants in Europe, with a total installed capacity of 2640 MW. Seawater is used as cooling fluid for heat exchangers and, at the end of the production process, discharged into the sea through an 80-m width channel with $100 \mathrm{~m}^{3} / \mathrm{s}$ flow (Gaeta et al., 2020). Seawater temperature of the effluent is estimated to be within $12{ }^{\circ} \mathrm{C}$ higher than the ambient value, and field measurements and effluent diffusion modelling showed that the increase in seawater temperature at $1 \mathrm{~m}$ depth varied from 0 to $4{ }^{\circ} \mathrm{C}$ with respect to the ambient values within $1 \mathrm{~km}$ radius from the effluent, depending on wind and wave direction (Gaeta et al., 2020).

\section{Materials and methods}

\section{Sampling design and sample processing}

Sampling was carried out in July 2015 at three locations 3-6 km far one each other, one putatively impacted by the thermal effluent, located at about $500 \mathrm{~m}$ north from the discharge channel (hereafter indicated as $I$ ), and two control locations (hereafter indicated as $\mathrm{C} 1$ and $\mathrm{C} 2$, and $C s$ altogether), to serve as unaffected reference conditions, positioned northward with respect to $I$ (Fig. 1). The absence of large patches of rocky reefs in the southern sector of the study area, prevented positioning at least one control location on both sides of the effluent. $\mathrm{C} 1$ and $\mathrm{C} 2$ were randomly selected from a set of potential control locations with environmental conditions (exposure, type of rocky substrate, depth) comparable to those characterizing rocky reefs at $I$ (Fig. 2). In each location, sampling was carried out at two sites (100-300 m apart) and, at each site, in three 


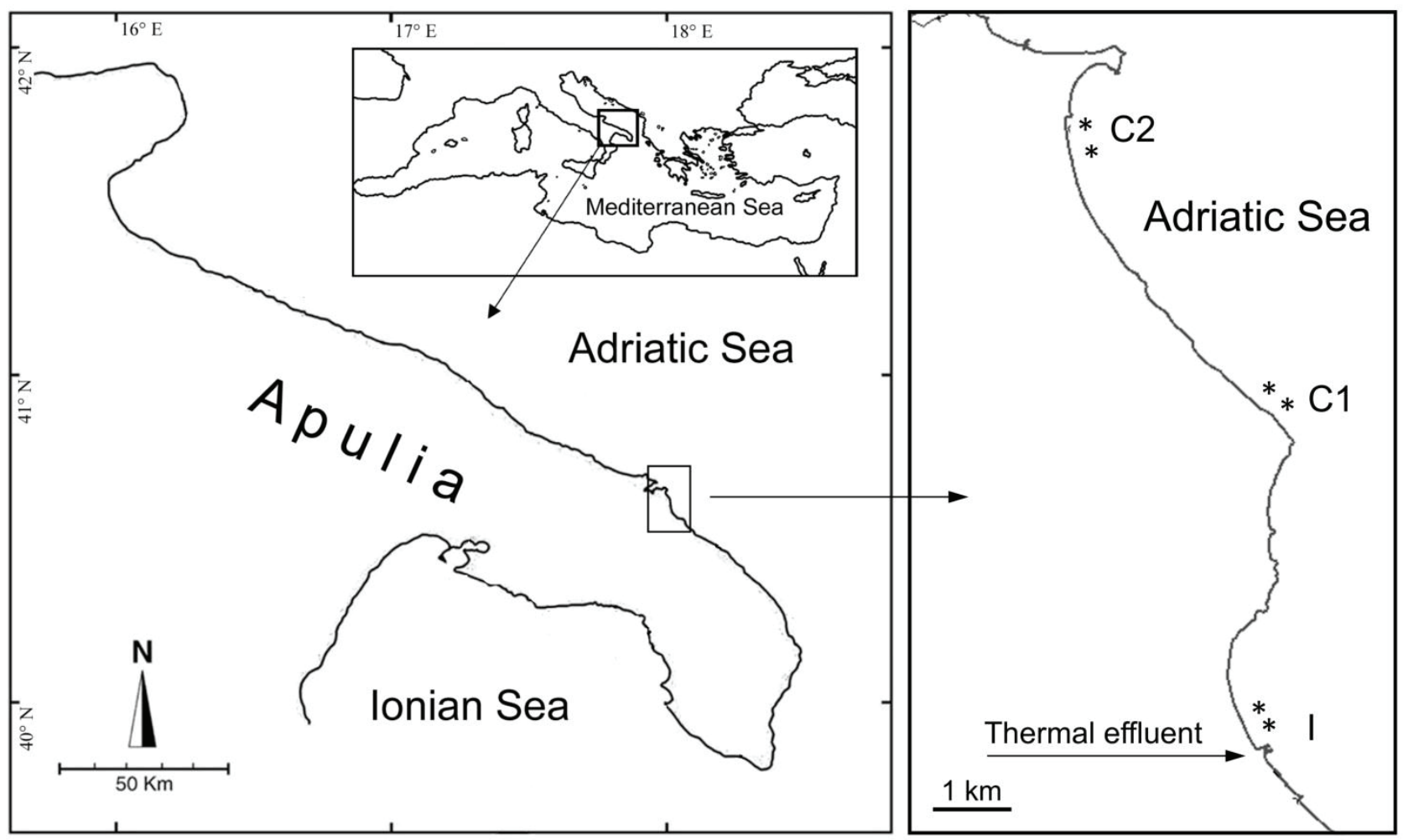

Fig. 1. Study area and position of the putatively impacted location $(I)$ and control locations $(\mathrm{C} 1$ and $\mathrm{C} 2)$. The position of sampling sites in each location were also indicated $(*)$
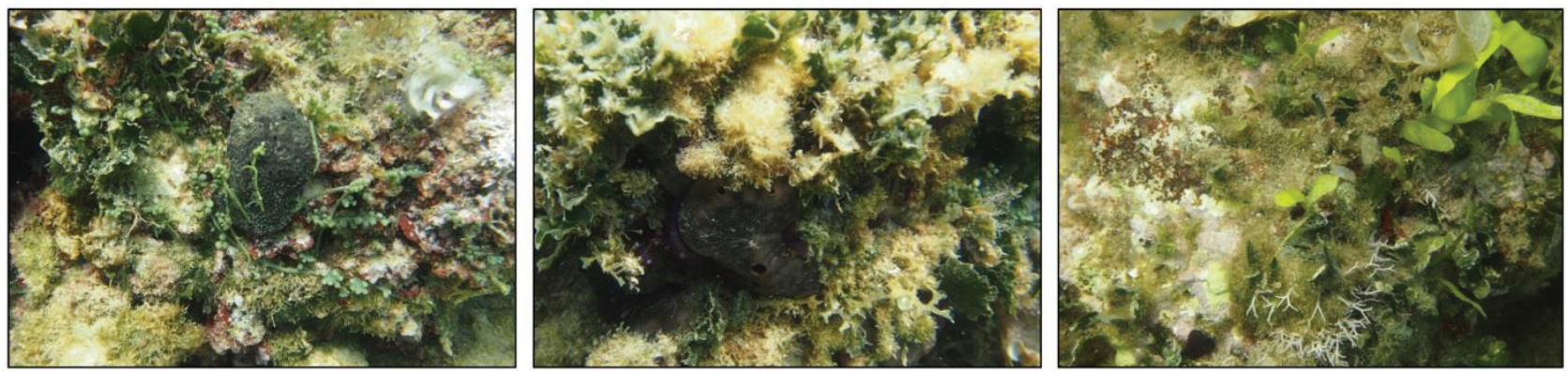

Fig. 2. Examples of macrobenthic assemblages characterizing C1 (left panel), C2 (central panel), and I (right panel)

sampling stations (10s $\mathrm{m}$ apart), in order to quantify the spatial variability of macrobenthic assemblages at a range of spatial scales. In each sampling station, sessile assemblages at approximately $5 \mathrm{~m}$ depth were sampled with $n=10$ random photographic replicate samples of $16 \times 23 \mathrm{~cm}$ each (Roberts et al., 1994), using a digital underwater camera Canon EOS 400D ${ }^{\mathrm{TM}}$ equipped with strobes, yielding a total of 180 photographic samples. Digital images were then analysed on the computer by superimposing a grid of 24 equally sized quadrats, to help estimating the $\%$ cover of sessile organisms in the photographic sample (Dethier et al., 1993). Vagile organisms were not considered in the analysis. A total of 53 taxa were found (Table 1). Most of them ( $90 \%)$ were identified at the level of species or genus. In some cases $(\sim 10 \%)$ organisms were collapsed into morphological groups due to the intrinsic difficulties of taxonomic identification from images.

\section{Statistical analysis}

Distance-based permutational multivariable analysis of variance (PERMANOVA, Anderson 2001) was used to test 
Table 1. List of taxa found in the study

\begin{tabular}{|c|c|c|c|}
\hline \multirow[t]{20}{*}{ Algae } & $\begin{array}{l}\text { Acetabularia acetabulum (Linnaeus) P.C. Silva, } 1952 \\
\text { Anadyomene stellata (Wulfen) C. Agardh, } 1823\end{array}$ & Cnidaria & $\begin{array}{l}\text { Aiptasia mutabilis (Gravenhorst, 1831) } \\
\text { Anemonia viridis (Forsskål, 1775) }\end{array}$ \\
\hline & Amphiroa rigida J.V. Lamouroux, 1816 & & $\begin{array}{l}\text { Balanophyllia (Balanophyllia) europaea } \\
\text { (Risso, 1826) }\end{array}$ \\
\hline & Caulerpa cylindracea Sonder, 1845 & & Cereus pedunculatus (Pennant, 1777) \\
\hline & Caulerpa prolifera (Forsskål) J.V. Lamouroux, 1809 & & Cladocora caespitosa (Linnaeus, 1767) \\
\hline & Ceramium sp. & & Clavularia sp. \\
\hline & Cladophora sp. & & Eudendrium sp. \\
\hline & Corallina sp. & & Sertularella sp. \\
\hline & Dictyota spp. & Annelida & Serpulids \\
\hline & Encrusting Corallines Rhodophytes (ECR) & Mollusca & Arca noae Linnaeus, 1758 \\
\hline & Filamentous Algae & & Dendropoma sp. \\
\hline & Flabellia petiolata (Turra) Nizamuddin, 1987 & & Ostrea sp. \\
\hline & $\begin{array}{l}\text { Halimeda tuna (J.Ellis \& Solander) J.V.Lamouroux, } \\
1816\end{array}$ & & Rocellaria dubia (Pennant, 1777) \\
\hline & Jania sp. & & Vermetus arenarius (Linnaeus, 1758) \\
\hline & Laurencia complex & Bryozoa & Calpensia nobilis (Esper, 1796) \\
\hline & Padina pavonica (Linnaeus) Thivy, 1960 & & Schizobrachiella sanguinea (Norman, 1868) \\
\hline & Peyssonnelia spp. & Tunicata & Aplidium sp. \\
\hline & Halopteris scoparia (Linnaeus) Sauvageau, 1904 & & Botrylloides sp. \\
\hline & $\begin{array}{l}\text { Tricleocarpa fragilis (Linnaeus) Huisman \& R.A. } \\
\text { Townsend, } 1993\end{array}$ & & Cystodytes dellechiajei (Della Valle, 1877) \\
\hline & Valonia macrophysa Kützing, 1843 & & Didemnum sp. \\
\hline & Aplysina aerophoba (Nardo, 1833) & & $\begin{array}{l}\text { Diplosoma listerianum (Milne Edwards, } \\
\text { 1841) }\end{array}$ \\
\hline \multirow{10}{*}{ Porifera } & Chondrilla nucula Nardo, 1847 & & Microcosmus sabatieri Roule, 1885 \\
\hline & Chondrosia reniformis Nardo, 1847 & & \\
\hline & Cliona celata Grant, 1826 & & \\
\hline & Cliona rhodensis Rützler \& Bromley, 1981 & & \\
\hline & Cliona viridis (Schmidt, 1862) & & \\
\hline & Crambe crambe (Schmidt, 1862) & & \\
\hline & Ircinia variabilis (Schmidt, 1862) & & \\
\hline & Petrosia (Petrosia) ficiformis (Poiret, 1789) & & \\
\hline & Phorbas fictitius (Bowerbank, 1866) & & \\
\hline & Sarcotragus spinosulus (Schmidt, 1862) & & \\
\hline
\end{tabular}


for differences between $I$ and $C s$. The analysis was based on Bray-Curtis dissimilarities (Bray \& Curtis, 1957) on untransformed data, and each term in the analysis was tested by 4999 random permutations of appropriate units. The design for the analysis comprised three factors: Location [Lo], random, with three levels, one impacted and two controls; Site [Si(Lo)], two levels, random, nested in Lo; and Station $[\mathrm{St}(\mathrm{Si}(\mathrm{Lo}))]$, three levels, random, nested in $\mathrm{Si}(\mathrm{Lo})$, with $n=10$ replicates. Due to the presence of a single putatively impacted location, the design was asymmetrical (Underwood, 1994). Thus, the location term was partitioned into two portions: the 1-d.f. fixed contrast of $I$-vs-Cs and the variability between $C s$. The same partitioning was also done for all the other terms in the analysis (e.g., the term $\mathrm{Si}(\mathrm{Lo})$ was partitioned into the two terms $\mathrm{S}(I)$ and $\mathrm{S}(C s))$. Finally, the residual variation was split in two portion, Res $I$ and Res $C s$, which is the variability for observations at $I$ and $C s$ respectively. Full details for variance partitioning and the choice of appropriate denominators for $F$ test in asymmetrical designs are provided in Terlizzi et al. (2005).

Non-metric multidimensional scaling ordination (nMDS) of centroids of stations based on the Bray-Curtis dissimilarity matrix was used to depict multivariate patterns of assemblages. Similarity Percentage analysis (SIMPER; Clarke, 1993) was also performed to evaluate the percent- age contribution of variables to Bray-Curtis dissimilarities of $I$-vs-Cs, allowing identifying taxa most contributing to differentiate assemblages at $I$-vs-Cs. Only variables whose contribution to dissimilarity was $\geq 1 \%$ were selected.

Analysis of variance (ANOVA) was done to test for differences in the mean total percentage cover and mean number of taxa between I-vs-Cs. The design for the analysis was the same as for PERMANOVA, asymmetrical, and thus implying the same variance partitioning. Prior to analysis, Cochran's $C$-test was performed to check the assumption of variance homogeneity (Underwood, 1997) and data were transformed to remove heteroscedasticity, if required.

Due to the relatively small number of degrees of freedom for some of the tests, and in consideration of the precautionary principle in environmental impact assessment, $\alpha=0.10$ was fixed a priori as a decision criterion for interpreting statistical results in both multivariate and univariate analyses (Gray, 1990; Fairweather, 1991).

Analysis was performed using the software package PRIMER v7 (Clarke \& Gorley, 2015), including the addon package PERMANOVA ${ }^{+}$(Anderson et al., 2008).

\section{Results}

Table 2. Results of asymmetrical PERMANOVA testing for differences between assemblages at the impacted location versus control locations based on Bray-Curtis dissimilarities (data untransformed) of multivariate data (53 taxa). Each test was performed using 4999 permutations of appropriate units. $P$-values given in italics were obtained using 4999 Monte Carlo samples from the asymptotic permutation distribution. The term used for the denominator mean square in each case is given in column $\mathrm{MS}_{\mathrm{DEN}}$

\begin{tabular}{|c|c|c|c|c|c|c|}
\hline Source of variation & d.f. & SS & MS & Pseudo- $F$ & $P$ & $\mathbf{M S}_{\mathrm{DEN}}$ \\
\hline Lo & 2 & 92934.5 & 46467.3 & 6.275 & 0.000 & $\mathrm{Si}(\mathrm{Lo})$ \\
\hline$I$-vs-Cs & 1 & 69444.0 & 69444.0 & 2.956 & 0.092 & $\mathrm{Cs}$ \\
\hline $\mathrm{Cs}$ & 1 & 23490.5 & 23490.5 & 3.311 & 0.042 & $\operatorname{Si}(C s)$ \\
\hline Si(Lo) & 3 & 22216.1 & 7405.4 & 2.736 & 0.001 & $\mathrm{St}(\mathrm{Si}(\mathrm{Lo}))$ \\
\hline $\operatorname{Si}(I)$ & 1 & 8026.1 & 8026.1 & 3.406 & 0.009 & $\operatorname{St}(\operatorname{Si}(I))$ \\
\hline $\operatorname{Si}(C s)$ & 2 & 14190.0 & 7095.0 & 2.462 & 0.018 & $\operatorname{St}(\operatorname{Si}(C s))$ \\
\hline $\mathrm{St}(\mathrm{Si}(\mathrm{Lo}))$ & 12 & 32479.3 & 2706.6 & 2.457 & 0.000 & Res \\
\hline $\operatorname{St}(\operatorname{Si}(I))$ & 4 & 9427.1 & 2356.775 & 1.600 & 0.031 & Res $I$ \\
\hline $\mathrm{St}(\mathrm{Si}(C s))$ & 8 & 23052.2 & 2881.5 & 3.146 & 0.000 & Res $C s$ \\
\hline Res & 162 & 178440.2 & 1101.5 & & & \\
\hline Res $I$ & 54 & 79525.3 & 1472.7 & & & \\
\hline Res $C s$ & 108 & 98914.9 & 915.9 & & & \\
\hline Total & 179 & 326070.1 & & & & \\
\hline
\end{tabular}


Multivariate analysis detected a significant effect of the thermal effluent in modifying the structure of sessile assemblages at the impact I-vs-Cs (Table 2). This was clearly depicted in the nMDS plot, where the site centroids of $I$ set apart from those of the two control locations that, instead, clustered together in the multivariate space (Fig. 3).

Twelve taxa contributed to explain $>90 \%$ of dissimilarity between assemblages in I-vs-Cs (Table 3). More specifically, the macroalgae Padina pavonica (L.) Thivy 1960, Caulerpa cylindracea Sonder 1845, Flabellia petiolata (Turra) Nizamuddin 1987, and articulated corallines of the genus Jania characterized control locations, while showing low to very low abundance at $I$ (Table 2). In contrast, Halimeda tuna (J. Ellis \& Solander) J.V. Lamouroux 1816, the morphological group of Filamentous Algae, and Caulerpa prolifera (Forsskål) J.V. Lamouroux 1809, mostly characterized assemblages at $I$, with the latter found exclusively at the impact location (Table 2).

No significant effects of the effluent on the mean total cover and the mean number of taxa were detected (Table 4, Fig. 4).

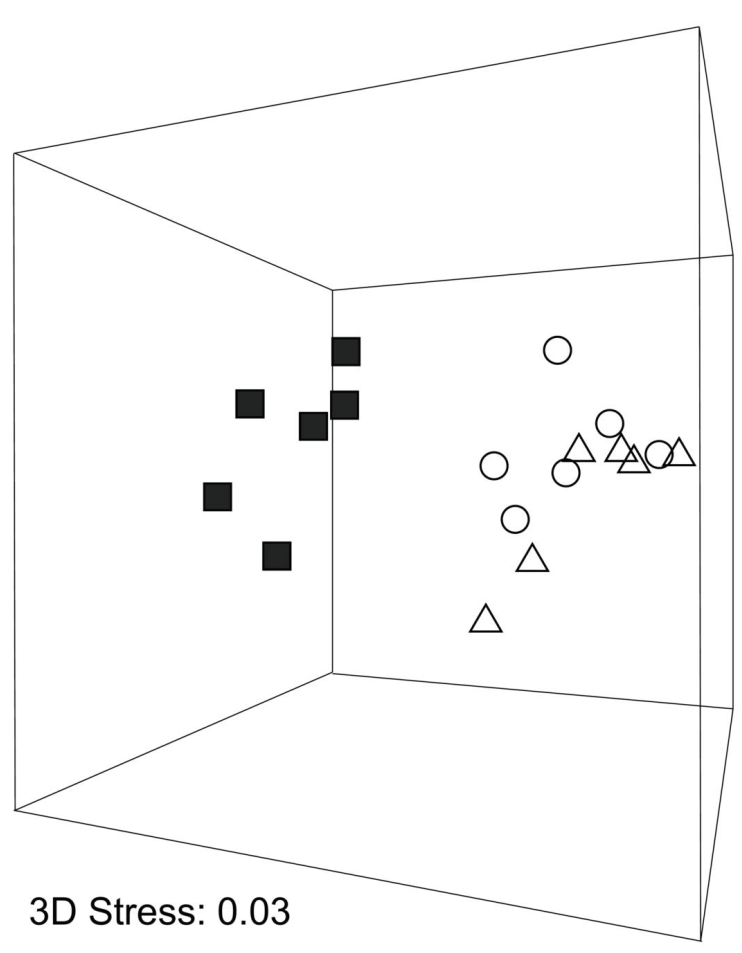

Fig. 3. 3-D non-metric multidimensional scaling ordination (nMDS) based on Bray-Curtis dissimilarities of site centroids for I (black squares), C1 (blank circles) and C2 (blank triangles)

Table 3. Summary of results of SIMPER analysis based on Bray-Curtis dissimilarities (data untransformed). Only taxa whose contribution to total dissimilarity between $I$-vs-Cs was equal or exceeded $1 \%$ were reported

\begin{tabular}{|c|c|c|c|c|}
\hline & Cs & I & & \\
\hline Taxon & Average abundance & $\begin{array}{c}\text { Average } \\
\text { abundance }\end{array}$ & $\begin{array}{l}\% \text { contribution to } \\
\text { dissimilarities }\end{array}$ & $\begin{array}{c}\text { Cumulative } \% \\
\text { contribution }\end{array}$ \\
\hline Padina pavonica & 19.9 & 11.4 & 16.1 & 16.1 \\
\hline Filamentous Algae & 7.1 & 21.0 & 14.1 & 30.2 \\
\hline Caulerpa cylindracea & 16.7 & 3.6 & 12.8 & 43.0 \\
\hline Flabellia petiolata & 9.9 & 1.1 & 8.9 & 51.9 \\
\hline Halimeda tuna & 2.7 & 9.3 & 7.5 & 59.4 \\
\hline Peyssonnelia spp. & 10.1 & 6.9 & 6.8 & 66.2 \\
\hline Caulerpa prolifera & 0.0 & 7.1 & 6.6 & 72.8 \\
\hline Jania spp. & 6.4 & 0.9 & 5.5 & 78.3 \\
\hline Dictyota spp. & 3.7 & 5.8 & 5.5 & 83.8 \\
\hline ECR & 1.6 & 4.3 & 4.2 & 88.0 \\
\hline Cliona celata & 0.2 & 1.3 & 1.4 & 89.4 \\
\hline Sarcotragus spinosulus & 0.5 & 0.9 & 1.2 & 90.6 \\
\hline
\end{tabular}



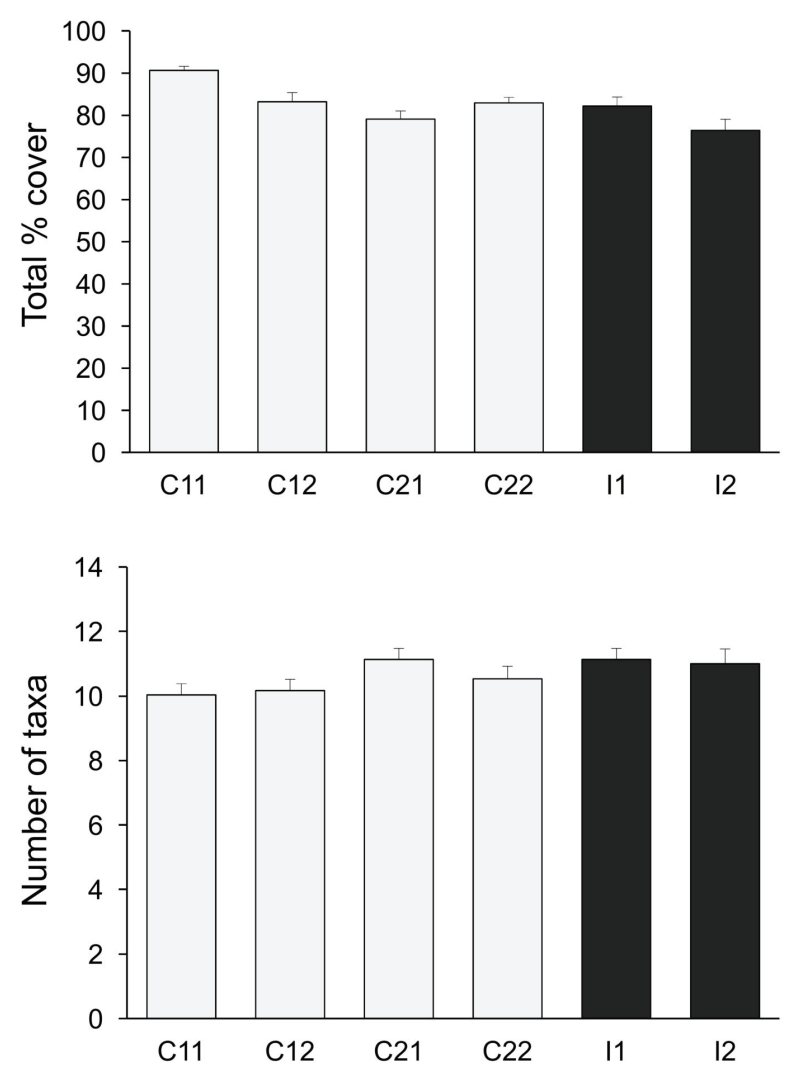

Fig. 4. Mean ( \pm SE, $n=30)$ total $\%$ cover and number of taxa for each of the two sites (indicated with 1 and 2) at $I$ (black bars), $\mathrm{C} 1$ and $\mathrm{C} 2$ (white bars)

\section{Discussion}

We detected a significant change between I-vs-Cs (at $\alpha=$ 0.10 ), indicating that the discharge of heated seawater from the effluent has the potential to alter the structure of nearby sessile assemblages with respect to unaffected areas. However, our data were limited to a single time of sampling preventing further considerations on temporal patterns of such changes. The effects of thermal discharge might be quite variable among seasons (Langford, 1990; Kim et al., 2013; Teixeira et al. 2012), and strongly dependent on the ambient temperature of seawater, which could contribute especially in the warm season to exacerbate the effects of heated waters on aquatic organisms, since sublethal and lethal limits can be more easily approximated (Langford, 1990). Further investigations are therefore needed to appreciate temporal variations in the effect of thermal discharge on macroinvertebrates and macroalgae inhabiting subtidal reefs.

In contrast to other studies (e.g., Teixeira et al., 2012), no effects of thermal discharge on total abundance and taxon richness were detected. This could depend on the fact that the stretch of coast where the effluent was positioned is particularly exposed to dominant winds and currents and subjected to an intense hydrodynamic regime, which contributed to enhance seawater mixing and helped dissipating the plume of heated waters. It is worth noting also that, the water body northward the effluent received

Table 4. Summary of results of asymmetrical ANOVA on mean total cover and number of taxa

\begin{tabular}{|c|c|c|c|c|c|c|c|}
\hline \multirow[b]{2}{*}{ Source of variation } & \multirow[b]{2}{*}{ d.f. } & \multicolumn{3}{|c|}{ Total \% cover } & \multicolumn{3}{|c|}{ No. of taxa } \\
\hline & & MS & $F$ & $P$ & MS & $F$ & $P$ \\
\hline Lo & 2 & 960.1 & 1.856 & 0.270 & 15.3 & 7.719 & 0.068 \\
\hline$I$-vs-Cs & 1 & 872.7 & 1.687 & 0.285 & 14.4 & 0.894 & 0.518 \\
\hline Cs & 1 & 1047.3 & 1.989 & 0.294 & 16.1 & 5.694 & 0.139 \\
\hline $\mathrm{Si}(\mathrm{Lo})$ & 3 & 517.4 & 2.661 & 0.098 & 2.0 & 0.399 & 0.753 \\
\hline $\operatorname{Si}(I)$ & 1 & 498.8 & 2.230 & 0.209 & 0.3 & 0.031 & 0.868 \\
\hline $\operatorname{Si}(C s)$ & 2 & 526.5 & 2.928 & 0.118 & 2.8 & 0.883 & 0.449 \\
\hline $\mathrm{St}(\mathrm{Si}(\mathrm{Lo}))$ & 12 & 194.2 & 1.803 & 0.052 & 5.0 & 1.196 & 0.293 \\
\hline $\mathrm{St}(\operatorname{Si}(I))$ & 4 & 223.6 & 1.275 & 0.322 & 8.5 & 1.863 & 0.129 \\
\hline $\mathrm{St}(\mathrm{Si}(C s))$ & 8 & 179.8 & 1.915 & 0.063 & 3.2 & 0.802 & 0.604 \\
\hline Res & 162 & 108.1 & & & 4.0 & & \\
\hline Res $I$ & 54 & 175.4 & & & 4.5 & & \\
\hline $\operatorname{Res} C s$ & 108 & 93.9 & & & 4.0 & & \\
\hline
\end{tabular}


the heated water only when winds blew from S-SE sectors (one of the main wind direction in the region, along with N-NE winds, Gaeta et al. 2020), so that rocky reef assemblages at $I$ were not permanently under the influence of thermal discharge.

The effect of heated seawater discharge, however, seemed to be strong enough to cause changes in composition of sessile assemblages and shifts in the relative abundance of dominant taxa between $I$ and control locations. This was mostly due to changes in the structure of macroalgal stands characterizing subtidal reefs close to the effluent, which were dominated by filamentous algae, $H$. tuna and $C$. prolifera, whereas $P$. pavonica, F. petiolata, articulated corallines, and $C$. cylindracea characterized control locations. Such changes could be related to the intrinsic thermal tolerance of the different species. C. prolifera and H. tuna, for instance, have been found to perform better in warmer waters, with higher optimal temperature or higher survival temperature limits with respect to other species, such as $P$. pavonica (Savva et al., 2018). Interestingly, $C$. cylindracea was more abundant at control locations, despite its relative insensitiveness in terms of growth rates and photosynthetic yield to increasing ambient temperature (Sampeiro-Ramos et al., 2015). Nevertheless, increased seawater temperature could have detrimental effects on the physiology of early thalli of this invasive species, causing a reduction of growth rates and photosynthetic efficiency if occurring during winter (Flagella et al., 2008), possibly explaining the reduced abundance at $I$.

The increase of seawater temperature is not the only stress associated to the effluent discharge, and other environmental alterations could have participated in determining the observed patterns. Other studies in the region highlighted that the increased hydrodynamism caused by the outflow, with the ensuing increase in resuspension of sediments, could affect macrobenthic assemblages nearby the effluent (Marano et al., 2000). The proliferation of filamentous algae at $I$, and found in other areas subjected to thermal discharge (e.g., Choi, 2008), can be interpreted as a symptom of generalized environmental stress caused by the increase in seawater temperature (Johnson et al., 2017; Dijkstra et al., 2019), turbidity and sedimentation which favored this group of tolerant and opportunistic algae (Airoldi, 1998).

The Mediterranean Sea is undergoing to increasing levels of human pressures threatening its unique marine biodiversity (Lejeusne et al., 2010; Micheli et al. 2013;), with non-native species introduction and climate change being the most alarming threats to this basin due to their potential to cause regime shifts to marine ecosystems (Rilov \& Galil, 2009; Mannino et al., 2017; Bevilacqua et al., 2019). Subtidal rocky reefs are of crucial importance for the functioning of coastal ecosystems and they are particularly sensitive to the ongoing environmental changes (Sala et al., 2011; Strain et al. 2014), which place this marine habitat among the most endangered ones at a basin scale (Bevilacqua et al., 2020). Our findings demonstrated that thermal pollution from coastal power plants could play a role in modifying the structure of sessile assemblages on subtidal reefs. Current rates of warming of the Mediterranean Sea could combine increasing the magnitude and the spatial extent of these effects, and potentially participating to drive undesirable ecological changes, stressing the need for further long-term assessments of the impact of point sources of thermal pollution on these important habitats.

\section{Acknowledgements}

This work was carried out in the frame of several monitoring programmes funded by the Province of Brindisi (Italy).

\section{References}

Airoldi L., 1998, Roles of disturbance, sediment stress, and substratum retention on spatial dominance in algal turf, Ecology 79: 2759-2770.

Anderson M.J., 2001, A new method for non-parametric multivariate analysis of variance, Austral Ecology 26: 32-46.

Anderson M.J., Gorley R.N., Clarke K.R., 2008, PERMANOVA+ for PRIMER: guide to software and statistical methods. PRIMER-E, Plymouth, UK.

Arieli R.N., Almogi-Labin A., Abramovich S., Herut B., 2011, The effect of thermal pollution on benthic foraminiferal assemblages in the Mediterranean shoreface adjacent to Hadera power plant (Israel), Marine Pollution Bulletin 62: 1002-1012.

Baker P., Fajans J.S., Arnold W.S., Ingrao D.A., Marell D.C., Baker S.M., 2007, Range and dispersal of a tropical marine invader, the asian green mussel, Perna viridis, in subtropical waters of the southeastern United States, Journal of Shellifish Research 26: 345-355.

Bamber R.N., 1990, Power station thermal effluents and marine crustaceans, Journal of Thermal Biology 15: 91-96.

Barnett P.R.O., 1972, Effects of Warm Water Effluents from Power Stations on Marine Life, Proceedings of the Royal Society of London. Series B, Biological Sciences 180: 497-509.

Bevilacqua S., Katsanevakis S., Micheli F., Sala E., Rilov G., Sarà G., Malak D.A., Abdulla A., Gerovasileiou V., Gissi E., Mazaris A.D., Pipitone C., Sini M., Stelzenmüller V., Terlizzi A., Todorova V., Fraschetti S., 2020, The status of coastal benthic ecosystems in the Mediterranean Sea: Evidence from ecological indicators. Frontiers in Marine Science 7: 475. 
Bevilacqua S., Savonitto G., Lipizer M., Mancuso P., Ciriaco S., Srijemsi M., Falace A., 2019, Climatic anomalies may create a long-lasting ecological phase shift by altering the reproduction of a foundation species, Ecology 100: e02838.

Bray J.R., Curtis J.T., 1957, An ordination of the upland forest communities of Southern Wisconsin, Ecological Monographs 27: 325-349.

Bush R.M., Welch E.B., Mar B.W., 1974, Potential effects of thermal discharges on aquatic systems, Environmental Science and Technology 6: 561-568.

Choi D.H., Park J.S., Hwang C.Y., Huh S.H., Cho B.C., 2002, Effects of thermal effluents from a power station on bacteria and heterotrophic nanoflagellates in coastal waters, Marine Ecology Progress Series 229: 1-10.

Choi H.-G., 2008, Effects of thermal effluents from Wolseong nuclear power plant on macroalgal composition and community structure, Algae 23: 151-162.

Clarke K.R., 1993, Nonparametric multivariate analyses of changes in community structure, Australian Journal of Ecology 18: 117-143.

Clarke K.R., Gorley R.N., 2015, PRIMER version 7: User manual/tutorial, PRIMER-E, Plymouth, UK.

Crema R., Bonvicini Pagliai A.M., 1980, The structure of benthic communities in an area of thermal discharge from a coastal power station, Marine Pollution Bulletin 11: $221-224$.

Deabes E.A.M., 2020, The impact of thermal power stations on coastline and benthic fauna: Case study of ElBurullus power plant in Egypt, Results in Engineering 7: 100128.

Dethier M.N., Graham E.S., Cohen S., Tear L.M., 1993, Visual versus random-point percent cover estimation: 'objective' is not always better, Marine Ecology Progress Series 96: 93-100.

Dijkstra J.A., Litterer A., Mello K., O’Brien B.S., Rzhanov Y., 2019, Temperature, phenology, and turf macroalgae drive seascape change: Connections to mid-trophic level species. Ecosphere 10: e02923.

Fairweather P.G., 1991, Statistical power and design requirements for environmental monitoring, Australian Journal of Marine and Freshwater Research 42: 555568.

Flagella M.M, Lorenti M., Buia M.C., 2008, Temperature response in a shallow-water Mediterranean population of Caulerpa racemosa var. cylindracea (Caulerpales, Chlorophyta), and a possible strategy of season anticipation, Botanica Marina 51: 278-284.

Gaeta M.G., Samaras A.G., Archetti R., 2020, Numerical investigation of thermal discharge to coastal areas: A case study in South Italy. Environmental Modelling \& Software 124: 104596.

Givan O., Edelist D., Sonin O., Belmaker J., 2018, Thermal affinity as the dominant factor changing Mediter- ranean fish abundances, Global Change Biology 24: 80-89.

Gray J.S., 1990, Statistics and the precautionary principle, Marine Pollution Bulletin 21:174-176.

Guarnieri G., Fraschetti S., Bogi C., Galil B.S., 2017, A hazardous place to live: spatial and temporal patterns of species introduction in a hot spot of biological invasions, Biological Invasion 19: 2277-2290.

Harvey B.P., Gwynn-Jones D., Moore P.J., 2013, Metaanalysis reveals complex marine biological responses to the interactive effects of ocean acidification and warming, Ecology and Evolution 3: 1016-1030.

Jiang Z., Zeng J., Chen Q., Huang Y., Xu X., Liao Y., Shou L., Liu J., 2009, Tolerance of copepods to short-term thermal stress caused by coastal power stations, Journal of Thermal Biology 33: 419-423.

Johnson M.D., Comeau S., Lantz C.A., Smith J.E., 2017, Complex and interactive effects of ocean acidification and temperature on epilithic and endolithic coral-reef turf algal assemblages. Coral Reefs 36: 1059-1070.

Katsanevakis S., Coll M., Piroddi C., Steenbeek J., Ben Rais Lasram F., Zenetos A., Cardoso A.C., 2014, Invading the Mediterranean Sea: biodiversity patterns shaped by human activities, Frontiers in Marine Science 1: 1-11.

Kim H.-G., Rho H.-S., Oh C.-W., 2013, Seasonal and spatial variations in nematode assemblages affected by thermal influence of nuclear power plant in Korea (East Sea, Pacific Ocean), Marine Biology Research 9: 725-738.

Langford T.E., 1990, Ecological Effects of Thermal Discharges, Elsevier, pp. 468.

Lejeusne C., Chevaldonné P., Pergent-Martini C., Boudouresque C.F., Pérez T., 2010, Climate change effects on a miniature ocean: the highly diverse, highly impacted Mediterranean Sea. Trends in Ecology and Evolution 25: 250-260.

Lin J., Zou X., Huang F., 2017, Effects of the thermal discharge from an offshore power plant on plankton and macrobenthic communities in subtropical China, Marine Pollution Bulletin 131: 106-114.

Lukšienė D., Sandström O., Lounasheimo L., Andersson J., 2000, The effects of thermal effluent exposure on the gametogenesis of female fish, Journal of Fish Biology 56: 37-50.

Mannino A., Balistreri P., Deidun A., 2017, The Marine Biodiversity of the Mediterranean Sea in a Changing Climate: The Impact of Biological Invasions, [in:] Mediterranean Identities - Environment, Society, Culture, F.-B. Borna (ed.), Intech Open, London.

Marano G., De Zio V., Pastorelli A.M., Rizzi E., Rositani L., Ungaro N., 2000, Effects of thermal discharge on marine ecosystems. A case study from a coastal power station in Southern Italy, Oebalia 26: 15-36. 
Micheli F., Halpern B.S., Walbridge S., Ciriaco S., Ferretti F., Fraschetti S., Lewison R., Nykjaer L., Rosenberg A.A., 2013, Cumulative human impacts on Mediterranean and Black Sea, marine ecosystems: Assessing current pressures and opportunities. PLoS ONE 8: e79889.

Rilov G., Galil B., 2009, Marine bioinvasions in the Mediterranean Sea-history, distribution and ecology, [in:] Biological Invasions in Marine Ecosystems, G. Rilov \& A.C. Crooks (eds), Springer, Berlin: 549-575.

Rivetti I., Fraschetti S., Lionello P., Zambianchi E., Boero F., 2014, Global warming and mass mortalities of benthic invertebrates in the Mediterranean Sea, PLoS ONE 9: e115655.

Roberts D.E., Fitzhenry S.R., Kennelly S.J., 1994, Quantifying subtidal macrobenthic assemblages on hard substrata using a jump camera method, Journal of Experimental Marine Biology and Ecology 177: 157-170.

Sala E., Kizilkaya Z., Yildirim D., Ballesteros E., 2011, Alien marine fishes deplete algal biomass in the eastern Mediterranean. PLoS ONE 6: e17356.

Samperio-Ramos G., Olsen Y.S., Tomas F., Marbà N., 2015, Ecophysiological responses of three Mediterranean invasive seaweeds (Acrothamnion preissii, Lophocladia lallemandii and Caulerpa cylindracea) to experimental warming, Marine Pollution Bulletin 96: 418-423.

Sanford E., 1999, Regulation of keystone predation by small changes in ocean temperature, Science 283: 2095-2097.

Savva I., Bennett S., Roca G., Jordà G., Marbà N., 2018, Thermal tolerance of Mediterranean marine macrophytes: Vulnerability to global warming, Ecology and Evolution 8: 12032-12043.

Strain E.M.A., Thomson R.J., Micheli F., Mancuso F.P., Airoldi L., 2014, Identifying the interacting roles of stressors in driving the global loss of canopy forming to mat-forming algae in marine ecosystems. Global Change Biology 20: 3300-3312.

Sylvester J.R., 1970, Possible effects of thermal effluents on fish: A review, Environmental Pollution 3: 205-215.

Teixeira T.P., Neves L.M., Araújo F.G., 2009, Effects of a nuclear power plant thermal discharge on habitat complexity and fish community structure in Ilha Grande Bay, Brazil, Marine Environmental Research 68: $188-195$.
Teixeira T.P., Neves L.M., Araújo F.G., 2012, Thermal impact of a nuclear power plant in a coastal area in Southeastern Brazil: effects of heating and physical structure on benthic cover and fish communities, Hydrobiologia 684: 161-175.

Terlizzi A., Benedetti-Cecchi L., Bevilacqua S., Fraschetti S., Guidetti P., Anderson M.J., 2005, Multivariate and univariate asymmetrical analyses in environmental impact assessment: a case study of Mediterranean subtidal sessile assemblages, Marine Ecology Progress Series 289: $27-42$.

Underwood A.J., 1994, On beyond BACI: sampling designs that might reliably detect environmental disturbances, Ecological Applications 4: 3-15.

Underwood A.J., 1997, Experiments in ecology: their logical design and interpretation using analysis of variances. Cambridge University Press, Cambridge.

Walther G.-R., Roques A., Hulme P.E., Sykes M.T., Pyšek P., Kühn I., Zobel M., Bacher S., Botta-Dukát Z., Bugmann H., Czúcz B., Dauber J., Hickler T., Jarošík V., Kenis M., Klotz S., Minchin D., Moora M., Nentwig W., Ott J., Panov V.E., Reineking B., Robinet C., Semenchenko V., Solarz W., Thuiller W., Vilà M., Vohland K., Settele J., 2009, Alien species in a warmer world: risks and opportunities, Trends in Ecology and Evolution 24: 686-693.

White D.P., Wahl D.H., 2020, Growth and physiological responses in largemouth bass populations to environmental warming: Effects of inhabiting chronically heated environments, Journal of Thermal Biology 88: 102467.

Wolf M.A., Sfriso A., Moro I., 2014, Thermal pollution and settlement of new tropical alien species: The case of Grateloupia yinggehaiensis (Rhodophyta) in the Venice Lagoon, Estuarine, Coastal and Shelf Science 147: 11-16.

World Power Plant Database, 2020, https://data.opendatasoft.com. Accessed Septembe, 20, 2020.

Yeruham E., Shpigel M., Abelson A., Rilov G., 2020, Ocean warming and tropical invaders erode the performance of a key herbivore, Ecology 101: e02925. 